Linha D'Água (Online), São Paulo, v. 33, n. 1, p. 1-8, jan.-abr. 2020

\title{
EDITORIAL
}

Rute Costa [htrps://orid.org/0000-0002-3452-7228]

Universidade NOVA de Lisboa, Lisboa, Portugal

Raquel Silva [htrps://orid.org/0000-0002-0505-4863]

Universidade NOVA de Lisboa - CLUNL, Lisboa, Portugal

Maria Inês Batista Campos [htrps://orid.org/0000-0003-0004-9923]

Universidade de São Paulo, São Paulo, SP, Brasil

\section{TERMINOLOGIA, UMA DISCIPLINA DE INTERFACES}

\section{A Terminologia numa perspetiva linguística e conceptual}

A Terminologia, uma disciplina que se caracteriza pela sua interdisciplinaridade, é de natureza bidimensional, linguística e conceptual. Qualquer trabalho terminológico ancorado nessa bidimensionalidade deve ter em conta essas duas dimensões, independentemente da abordagem metodológica utilizada - semasiológica ou onomasiológica - para a "systematic collection, description, processing and presentation of concepts and their designations" (ISO 1087: 2019, p.13). Qualquer que seja a abordagem, o terminológo deve, em determinado momento, identificar o termo e o conceito designado (semasiologia), ou então, o conceito e o termo que o designa (onomasiologia), a definição textual possibilitando a estabilização da relação entre um e outro.

O texto desempenha um papel central nesta abordagem. Nele, encontramos termos, marcadores linguísticos que manifestam a existência dos conceitos denotados pelos termos ou, ainda, elementos linguísticos que indicam as características que constituem os conceitos denotados pelos termos presentes nos textos, definições contextuais e contextos definitórios (Ramos \& Costa 2018). 
Linha D'Água (Online), São Paulo, v. 33, n. 1, p. 1-8, jan.-abr. 2020

Utilizar os textos como ponto de partida pressupõe a identificação dos termos, ou seja, das unidades lexicais que designam conceitos. Esta tarefa a priori óbvia é, do ponto de vista linguístico, uma fase complexa porque pressupõe a existência de critérios para diferenciar os termos dos não termos. Consideramos por não termo qualquer combinatória lexical que, do ponto de vista morfossintático, possa ser confundida com um termo - designação verbal de um conceito - mas que não o é, por essa combinatória lexical não ser designativa (Costa 2017).

$\mathrm{Na}$ classe dos não termos, incluímos as colocações e fraseologias terminológicas. Devemos, assim, poder decidir se as entidades lexicais recuperadas - que, do ponto de vista morfossintático, correspondem a possíveis estruturas de termos - o são de facto, isto é, se as estruturas lexicais identificadas designam conceitos que, segundo a (ISO 1087: 2019, p.3) são definidos como uma "unit of knowledge created by a unique combination of characteristics".

Nesta perspetiva da dupla dimensão da Terminologia, além do conhecimento sobre a língua, precisamos também do conhecimento dos especialistas da área de estudo em causa, que possam corresponder às solicitações dos terminólogos, para ajudar a organizar e validar a informação terminológica recolhida, com a finalidade de alimentar os recursos terminológicos e lexicográficos com conteúdos linguísticos e terminológicos de qualidade.

\section{A propósito de semântica e morfologia em Terminologia}

Independentemente das teorias que sustentam as metodologias utilizadas em Terminologia, a descrição linguística dos termos e das combinatórias linguísticas ditas de especialidade, revelam-se ser, quase sempre, o cerne da questão. É certamente o ponto problemático da discussão, mas também, a zona de maior proficiência para a reflexão sobre outras abordagens teóricas, ou o espaço para o esboço de novas metodologias de análise.

Os aspetos de semântica e morfologia, nas suas variadíssimas abordagens teóricas em Terminologia estão no centro da dinâmica descritiva das línguas de especialidade, sendo um contributo fundamental para o enriquecimento da 
Linha D’Água (Online), São Paulo, v. 33, n. 1, p. 1-8, jan.-abr. 2020

Terminologia, nas diversas interfaces que estabelece na ligação das ciências da linguagem com as áreas do conhecimento.

Esta publicação tem por objetivo reunir artigos de enfoque científico, em que se explore diferentes perspetivas de descrição das terminologias em diversas áreas do conhecimento, quer numa ótica monolingue, quer multilingue. Foi dada primazia à apresentação de reflexões teóricas e análises linguísticas com impacto na Terminologia ou, ainda, à apresentação de reflexões metodológicas conducentes à descrição de dados terminológicos (termos, colocações, fraseologias, definições, contextos).

Dos artigos submetidos, selecionámos os artigos cujas análises semânticas e morfológicas dos dados terminológicos contribuem de forma significativa para um maior conhecimento, na compreensão de fenómenos linguísticos e terminológicos atuais, visando uma organização lexical ou conceptual, com vista à construção de recursos lexicais de especialidade ou à exposição de fenómenos contemporâneos nas línguas de especialidade.

De entre as diversas problemáticas, foram privilegiadas questões de semântica lexical e de morfologia de especialidade que conduzem à reflexão sobre os mecanismos linguísticos subjacentes à formação de termos, colocações e fraseologias de especialidade, não perdendo de vista a neologia semântica, neologia formal ou a criatividade lexical em Terminologia.

Por outro lado, foram ainda contemplados os artigos com reflexões apontando para a exploração de corpora de especialidade, com vista ao tratamento automático de dados terminológicos, assim como aplicações nas áreas do ensino, da criação de recursos linguísticos e terminológicos para fins lexicográficos, de comunicação ou de redação técnicas ou, ainda, de tradução.

\section{Acerca do número 33/1 da revista Linha d'Água}

No seguimento dos estudos desenvolvidos já há longos anos, na USP, sobre neologia em português do Brasil, Lucimara Alves Costa e Ieda Maria Alves apresentam um artigo intitulado Um estudo do termo fiscal na terminologia da Economia: processos de formação e informaçôes conceituais, em que espelham uma metodologia de análise a 
Linha D’Água (Online), São Paulo, v. 33, n. 1, p. 1-8, jan.-abr. 2020

partir da ocorrência do termo fiscal, num corpus de economia, com o intuito de verificar os padrões de formação mais recorrentes constituídos por este adjetivo.

Com especial enfoque nas informações semânticas veiculadas pelos termos e nos processos de formação dos mesmos, o estudo evidencia os passos metodológicos conducentes a uma maior caracterização e conhecimento da terminologia da economia, em português do Brasil. De entre os fenómenos observados, o emprego de metáforas conceptuais surge como um aspeto predominante, permitindo conduzir a reflexão para o entendimento de novos factos linguísticos e processos estruturantes do pensamento científico.

Tratar os termos da informática numa perspetivação bilingue Português / Árabe, com o objetivo de criar um dicionário bilingue, destinado a universitários e profissionais da tradução, é o tema proposto por Abdesslam Okab em Abordagem semântica e morfológica a termos informáticos num dicionário bilingue Português Europeu - Arabe Padrão". O autor tem em conta as interfaces morfológicas e semânticas existentes nas equivalências entre ambas as línguas em foco, para descrever o processo de acolhimento das unidades terminológicas do domínio da informática e estabelecer os equivalentes correspondentes, no árabe padrão, à terminologia informática comum do português de Portugal.

As suas conclusões evidenciam que no português europeu, o recurso aos empréstimos do inglês são recorrentes, enquanto que no árabe padrão a tendência é arabizar recorrendo a decalques semânticos com palavras do seu próprio léxico, por se tratar de uma língua padronizada, visto que as línguas de fala espontânea nos países árabes usam sobretudo os empréstimos do inglês.

Noutra perspetiva, a da didática da tradução, o artigo, da autoria de Christina Dechamps em Data-Driven Learning, termes et collocations terminologiques: un défi pour la formation en traduction juridique, centra-se na importância da formação dos tradutores no uso correto de termos e colocações terminológicas, tendo por base numa abordagem principalmente inspirada nos princípios do Data-Driven Learning. São demonstradas as vantagens científicas e pedagógicas desta metodologia na aquisição de competências estratégicas em tradução.

Assente em técnicas que favorecem o desempenho do estudante no seu próprio processo de ensino/aprendizagem, assim como o desenvolvimento de um 
Linha D’Água (Online), São Paulo, v. 33, n. 1, p. 1-8, jan.-abr. 2020

espírito crítico, o processo inicia-se com uma abordagem linguística do texto, e é conduzido até à tradução final, marcando passo, em particular, nas dificuldades sentidas pelo aluno, em relação às colocações e às fraseologias de especialidade, ocorrências típicas das áreas especializadas do conhecimento.

Com enfoque diferente, virado para o tratamento automático da língua, Chiara Barbero e Raquel Amaro, em Exploração de corpora para extração e descrição de léxico de especialidade: para uma metodologia sólida e sustentada, expõem uma metodologia para a extração de léxico de especialidade e de relações léxico-semânticas, a partir de corpora, fazendo uso de várias informações linguísticas, categoria morfossintática, padrões léxico-sintáticos e organização textual.

A experiência é levada a cabo no contexto da exploração de corpora bilingue português/italiano, no domínio da Arte Pública, com vista à extração e descrição do léxico de especialidade com garantia de qualidade, propondo a maior automatização possível e conjugando abordagens linguísticas e estatísticas sem, contudo, comprometer a qualidade da análise linguística.

Com Daniel Marra, no seu artigo Cerrado e Vereda: designação, sentido e mudança semântica, entramos no mundo dos processos de criação lexical e da teoria semântica numa perspetiva diacrónica, com enfoque na metáfora e na metonímia, em torno da análise das unidades lexicais Cerrado e Vereda, vocábulos que designam, respetivamente, o segundo maior bioma brasileiro e um de seus subsistemas.

As conclusões apresentadas evidenciam que o estudo da "história" de uma palavra ajuda a perceber tanto a singularidade de sua constituição morfo-fonológica e semântica, quanto a da sua relação com o objeto que nomeia. Foi, assim, pertinentemente lançada a discussão sobre o tema da mudança semântica, com destaque para a metáfora e a metonímia, como fenómenos dinamizadores destes processos.

Olhando para fenómenos de neologia lexical, Rove Chishman, Aline Nardes dos Santos e Paola Martins apresentam uma abordagem aos neologismos produzidos no período das eleições realizadas no Brasil, em 2018, em O fenômeno da neologia lexical nas eleiçôes de 2018. O objetivo é apresentar uma metodologia que se baseia nos princípios de análise estabelecidos pelo Observatório de Neologia do Português (ONP). 
Linha D'Água (Online), São Paulo, v. 33, n. 1, p. 1-8, jan.-abr. 2020

Os neologismos foram, assim, identificados e submetidos a critérios de classificação morfológica, por sistematização de processos de formação. Os resultados apresentados evidenciam a criação de neologismos que remetem para o domínio da política. Foram, com esta investigação, identificados cerca de 73 neologismos, que vieram enriquecer o léxico de especialidade e integram, agora, o Glossário Neopolitiquês, um recurso construído como atividade pedagógica realizada na disciplina de Fundamentos de Morfologia.

Por sua vez, Juan Carlos Díaz Vásquez, apresenta-nos uma breve visão histórica do desenvolvimento das línguas técnicas e científicas no seu artigo Preâmbulo bistórico das linguas técnicas e cientificas: Surgimento de terminologia e normas internacionais, para explicar de que forma a língua sofre transformações, em consonância com o avanço do conhecimento e das técnicas.

$\mathrm{O}$ autor debruça-se sobre os fatores que originam a mudança de paradigmas na abordagem a essas linguagens e, em especial, destaca quais os contributos da Terminologia e do trabalho terminológico para tais fatores de mudança. Mostra como evidência, que a Terminologia contemporânea surgiu precisamente como uma resposta às necessidades industriais, forjando o seu próprio caminho, ao lado da linguística e da lexicologia aplicadas.

Com o artigo $A$ Terminologia: um instrumento ao serviço da inovação pedagógica no Espaço Europeu do Ensino Superior, Rosa Maria Fréjaville traz mais um contributo significativo sobre a importância da Terminologia em formações multilingues especializadas, no âmbito do ensino das línguas aplicadas, no ensino superior (em particular em França). Estuda a relação entre a metodologia terminológica e o ensino das línguas estrangeiras, apontando a sua relevância no âmbito do Quadro Europeu Comum de Referência para as Línguas.

Fazendo uma contextualização dos aspetos relevantes da política linguística da União Europeia, a autora, descreve o papel da Terminologia nas formações de ensino superior e sua ação, no que concerne à harmonização e à internacionalização das universidades. Mostra que este novo paradigma implica uma mudança de postura do professor e do aluno, assim como a utilização de estratégias de desenvolvimento de uma "metamemória" com o apoio da metodologia da Terminologia. 
Linha D’Água (Online), São Paulo, v. 33, n. 1, p. 1-8, jan.-abr. 2020

A Terminologia é, como aqui fica claramente espelhado, uma disciplina que oferece diferentes abordagens teóricas e metodologias de trabalho muito diversificadas, em função dos objetivos de estudo e dos públicos a quem se dirige.

Aspetos de descrição morfológica e aspetos de descrição semântica estão sempre na base da observação da dinâmica denominativa e da criatividade lexical nas línguas de especialidade e, em particular, em Terminologia, daí a importância da promoção deste campo de investigação tao fundamental para os lexicólogos e os terminólogos.

Permite um olhar mais focado sobre a descrição da unidade lexical, em contextos de especialidade, avaliando a sua composição morfológica e a sua evolução semântica. Permite um olhar sobre o termo enquanto unidade que veicula um conceito por via de uma designação. Permite, ainda, combinar análises de estruturas morfossemânticas de maior extensão, tais como as colocações terminológicas ou as fraseologias.

Assim, consideramos, que a riqueza das propostas de investigação e dos resultados apresentados neste número, são um valioso contributo que ilustra perfeitamente as múltiplas interfaces da Terminologia na ligação que estabelece entre as ciências da linguagem e as áreas do conhecimento.

Para finalizar, gostaríamos de deixar um sincero agradecimento aos autores Lucimara Alves Costa, Ieda Maria Alves, Abdesslam Okab, Christina Dechamps, Chiara Barbero, Raquel Amaro, Daniel Marra, Rove Chishman, Aline Nardes dos Santos, Paola Martins, Juan Carlos Díaz Vásquez e Rosa Maria Fréjaville, por terem respondido calorosamente ao desafio lançado para este número 33/1 da revista Linha d'Água, cujo fio condutor era as problemáticas em torno de questões de semântica e de morfologia em Terminologia.

A publicação deste número recebe o auxílio do Programa de Apoio às $\mathrm{Pu}$ blicações Científicas Periódicas da Universidade de São Paulo/SIBi, a quem agradecemos por permitir a indexação de Linha d'Água na Web of Science, base de dados de citações científicas do Institute for Scientific Information, mantida pela Clarivate Analytics, nas áreas de Ciências Sociais, Artes e Humanidades.

A revista conta com pareceristas do Conselho Editorial e ad hoc e com um corpo de revisores de língua portuguesa de excelência, o que garante sua alta 
Linha D'Água (Online), São Paulo, v. 33, n. 1, p. 1-8, jan.-abr. 2020

qualidade. Conta também com o trabalho de revisão de tradução, realizado pela professora Roseli Serra, da Universidade Católica de Pernambuco.

Com este número da revista, o Conselho Editorial busca a internacionalização do periódico, uma vez que recebemos artigos de autores de universidades estrangeiras, procurando responder às exigências da Universidade de São Paulo e das agências internacionais. Linha d'Água torna-se, assim, um espaço aberto a publicações ligadas aos estudos de língua portuguesa, aos estudos linguístico-discursivos e sua relação com o ensino, mantendo um diálogo constante com as pesquisas desenvolvidas no Brasil e no exterior.

\section{Referências}

COSTA, R. (2017), «Les collocations terminologiques », Habilitation à diriger des recherches, Lexicologie, Lexicographie, Terminologie, Lisbonne : FCSH NOVA.

ISO 704 : 2009 (F), Principes et méthodes de la terminologie. Geneva. International Organization for Standardization.

ISO 1087 :2019 (F), Terminology work and terminology science — Vocabulary. Geneva. International Organization for Standardization.

RAMOS, M; COSTA, R. (2018), «Semantic analyses of texts for eliciting and representing concepts: the TermCork project ». Terminologica. Éditeur : USBM, p. 167-199.

SILVA, R ; COSTA, R. (2020), "Accéder aux connaissances des experts par l'entremise de la médiation en Terminologie", in "L'essentiel de la médiation. Le regard des sciences humaines et sociales ", Direction de Michele De Gioia e Mario Marcon, Ed. Peter Lang, Belgique, p. $105-122$.

Lisboa, 29 de março de 2020. 